\title{
Application of Dual-Energy Spectral Computed Tomography to Thoracic Oncology Imaging
}

Cherry Kim, MD, $P h D^{1}$, Wooil Kim, $M D^{2}$, Sung-Joon Park, $M D^{3}$, Young Hen Lee, MD, PhD ${ }^{1}$, Sung Ho Hwang, MD, PhD ${ }^{4}$, Hwan Seok Yong, MD, PhD ${ }^{5}$, Yu-Whan Oh, MD, PhD ${ }^{4}$, Eun-Young Kang, MD, PhD ${ }^{4}$, Ki Yeol Lee, MD, PhD ${ }^{1}$

${ }^{1}$ Department of Radiology, Korea University Ansan Hospital, Korea University College of Medicine, Ansan, Korea; ${ }^{2}$ Department of Radiology and Center for Imaging Science, Samsung Medical Center, Sungkyunkwan University School of Medicine, Seoul, Korea; ${ }^{3}$ Department of Radiology, Hallym University Sacred Heart Hospital, Hallym University College of Medicine, Anyang, Korea; 'Department of Radiology, Korea University Anam Hospital, Korea University College of Medicine, Seoul, Korea; ${ }^{5}$ Department of Radiology, Korea University Guro Hospital, College of Medicine Korea University, Seoul, Korea

Computed tomography (CT) is an important imaging modality in evaluating thoracic malignancies. The clinical utility of dual-energy spectral computed tomography (DESCT) has recently been realized. DESCT allows for virtual monoenergetic or monochromatic imaging, virtual non-contrast or unenhanced imaging, iodine concentration measurement, and effective atomic number $\left(Z_{\text {eff }}\right.$ map). The application of information gained using this technique in the field of thoracic oncology is important, and therefore many studies have been conducted to explore the use of DESCT in the evaluation and management of thoracic malignancies. Here we summarize and review recent DESCT studies on clinical applications related to thoracic oncology.

Keywords: Dual-energy CT; Spectral CT; Lung cancer; Oncology

\section{INTRODUCTION}

Dual-energy spectral computed tomography (DESCT) has recently re-emerged as an advance in computed tomography (CT). It offers important new functional and specific information. Although the concept of dual-energy CT was initially developed in 1973 (1), this technique was underutilized for decades due to technical limitations and workflow issues (2). However, this technique has rapidly gained popularity after the development of a firstgeneration dual-source CT system in 2006, which can

Received: September 25, 2019 Revised: January 16, 2020

Accepted: February 10, 2020

Corresponding author: Ki Yeol Lee, MD, PhD, Department of Radiology, Korea University Ansan Hospital, Korea University College of Medicine, 123 Jeokgeum-ro, Danwon-gu, Ansan 15355, Korea.

- Tel: (8231) 412-5227 - Fax: (8231) 412-4264

- E-mail: kiylee@korea.ac.kr

This is an Open Access article distributed under the terms of the Creative Commons Attribution Non-Commercial License (https://creativecommons.org/licenses/by-nc/4.0) which permits unrestricted non-commercial use, distribution, and reproduction in any medium, provided the original work is properly cited. improve material differentiation by using two different $\mathrm{X}$-ray energy spectra. Current DESCT acquisition methods comprise of dual tubes either with or without beam filtration, rapid voltage switching with a single tube, a dual-layer detector with a single tube, a single tube with a split filter, or a single tube with sequential dual scans (2).

DESCT can provide both material-nonspecific and material-specific energy-dependent information as follows (2): 1) virtual monoenergetic or monochromatic imaging (VMI), 2) virtual non-contrast or unenhanced imaging (VNC), 3) iodine concentration (IC) measurement, and 4) effective atomic number ( $Z_{\text {eff }}$ map). Moreover, recent computing developments have led to a shortened reconstruction time using DESCT data. Because of these technical developments, the use of DESCT is rapidly increasing in routine clinical practice, and its clinical utility in the diagnosis, management, and evaluation of response to therapy in thoracic malignancies has expanded. Here we summarize and review recent studies of DESCT in its clinical applications related to thoracic oncology. In addition, Table 1 summarizes the clinical application of DESCT according to DESCT techniques. 
Table 1. Summary of Clinical Application of DESCT according to DESCT Techniques

\begin{tabular}{|c|c|c|c|}
\hline DESCT Technique & Clinical Application & Examples & References \\
\hline \multirow[t]{5}{*}{ VMI } & Artifact and noise reduction & - Improved image quality by decreasing metal or beam-hardening artifacts & $(5-10)$ \\
\hline & & $\begin{array}{l}\text { - Improved visualization of soft tissue lesions by decreasing image noise } \\
\text { and increasing SNR and CNR }\end{array}$ & \\
\hline & Contrast enhancement & $\begin{array}{l}\text {-VMI with low energy increased detectability, visibility, and correct } \\
\text { measurement of LNs and improved accuracy of diagnosing LN metastasis }\end{array}$ & $(11-15)$ \\
\hline & & $\begin{array}{l}\text { - Detection of inconspicuous osteoblastic metastases of vertebra from lung } \\
\text { cancers }\end{array}$ & \\
\hline & & $\begin{array}{l}\text {-VMI with high energy resulted in low attenuation and nodule volumes, } \\
\text { while VMI with low energy resulted in higher attenuation and nodule } \\
\text { volumes (possibility of over/under-estimation should be considered) }\end{array}$ & \\
\hline \multirow[t]{4}{*}{ VNC } & Evaluation of mediastinal LNs & $\begin{array}{l}\text { - Moderate agreement between TNC and VNC in evaluation of CT attenuation } \\
\text { of mediastinal LNs } \\
\text { - May underestimate calcification in SPN or mediastinal LNs in VNC } \\
\text { compared to TNC }\end{array}$ & $(16,17)$ \\
\hline & $\begin{array}{l}\text { Evaluation of intratumoral } \\
\text { hemorrhage }\end{array}$ & $\begin{array}{l}\text { - Intratumoral hemorrhage can be detected in patents with NSCLC treated } \\
\text { with anti-angiogenic agents }\end{array}$ & $(18)$ \\
\hline & $\begin{array}{l}\text { Virtual non-calcium reconstruction } \\
\text { for diagnosing vertebral metastasis }\end{array}$ & $\begin{array}{l}\text { - Effectively suppressed calcium in multi-level vertebra by replacing } \mathrm{HU} \\
\text { of voxels containing calcium with virtual } \mathrm{HU} \text { value as similar as possible } \\
\text { to expected } \mathrm{HU} \text { without calcium contribution }\end{array}$ & $(19)$ \\
\hline & Evaluation of adrenal masses & $\begin{array}{l}\text { - Identified adrenal adenomas with } 91 \% \text { sensitivity and } 100 \% \text { specificity } \\
\text { based on typical imaging features (non-contrast attenuation < } 10 \mathrm{HU} \text { ) }\end{array}$ & $(20)$ \\
\hline \multirow[t]{5}{*}{$\begin{array}{l}\text { IC } \\
\text { measurement }\end{array}$} & $\begin{array}{l}\text { Differentiation between malignant } \\
\text { and benign lesions }\end{array}$ & $\begin{array}{l}\text { - Different IC parameters between malignant and benign lung lesions } \\
\text { - Different IC parameters between LNs metastasis and benign LNs } \\
\text { - Different IC parameters between different LN diameters (normal: }<10 \mathrm{~mm} \text {; } \\
\text { intermediate: } \geq 10 \mathrm{~mm} \text { to }<15 \mathrm{~mm} \text {; enlarged: } \geq 15 \mathrm{~mm} \text { ) }\end{array}$ & $(20,21),(25-32)$ \\
\hline & $\begin{array}{l}\text { Differentiation of tumors, subtypes, } \\
\text { pathologic grades, and molecular }\end{array}$ & $\begin{array}{l}\text { - Different IC parameters according to histologic subtypes and pathologic } \\
\text { grades of lung cancers }\end{array}$ & $(23),(28),(33-38)$ \\
\hline & subcategories of lung cancers & $\begin{array}{l}\text { - Significant negative correlation between IC parameters and pathological } \\
\text { grades of NSCLC } \\
\text { - Different IC parameters between pulmonary metastases from different } \\
\text { primary origins } \\
\text { - Different IC parameters between low-risk thymomas from other thymic } \\
\text { tumors }\end{array}$ & \\
\hline & $\begin{array}{l}\text { Treatment response evaluation with/ } \\
\text { without correlation with positron } \\
\text { emission tomography-CT }\end{array}$ & $\begin{array}{l}\text { - IC parameters evaluating therapeutic effects in lung cancers or } \\
\text { mediastinal metastatic LNs } \\
\text { - Correlation between IC parameters and metabolic uptake in PET-CT and } \\
\text { association with tumor recurrence }\end{array}$ & $(39-45)$ \\
\hline & $\begin{array}{l}\text { Parenchymal perfusion defects due } \\
\text { to central lung cancers or PTE }\end{array}$ & $\begin{array}{l}\text { - Significant decrease in IC of pulmonary perfusion defects induced by } \\
\text { central lung cancer or PTE }\end{array}$ & $(20),(46)$ \\
\hline $\begin{array}{l}\text { Effective atomic } \\
\text { number }\left(Z_{\text {eff }} \text { map) }\right.\end{array}$ & $\begin{array}{l}\text { Not clear, but may differentiate } \\
\text { tumors }\end{array}$ & $\begin{array}{l}\text { - Significantly greater } Z_{\text {eff }} \text { was measured in benign thyroid nodules than } \\
\text { in papillary carcinomas } \\
\text { - Higher } Z_{\text {eff }} \text { was exhibited in soft tissue sarcomas than in normal tissues } \\
\text { - Lower minimum } Z_{\text {eff }} \text { and normalized mean } Z_{\text {eff }} \text { were statistically correlated } \\
\text { with malignant lung tumors } \\
\text { - Different } Z_{\text {eff }} \text { between squamous cell cancer, adenocarcinoma, and } \\
\text { neuroendocrine tumors }\end{array}$ & $(23),(47-49)$ \\
\hline
\end{tabular}

CNR = contrast-to-noise ratio, DESCT $=$ dual-energy spectral computed tomography, $\mathrm{HU}=$ Hounsfield unit, $\mathrm{IC}=$ iodine concentration, $\mathrm{LN}=$ lymph node, $\mathrm{NSCLC}=$ non-small cell lung cancer, $\mathrm{PET}-\mathrm{CT}={ }^{18} \mathrm{~F}$-fluorodeoxyglucose positron emission tomography, $\mathrm{PTE}=$ pulmonary thromboembolism, SNR = signal-to-noise ratio, SPN = solitary pulmonary nodules, $\mathrm{TNC}=$ true non-enhanced imaging, VMI = virtual monoenergetic or monochromatic imaging, $\mathrm{VNC}=$ virtual non-contrast or unenhanced imaging 
VMI

VMI can be synthesized using DESCT scans by decomposing two basis materials based on projection-based or imagebased methods. With single-source DESCT, VMI datasets are obtained in the projection-based domain, because these imaging data are acquired at the same projection angle (3). Contrastingly, with the dual-source platform, approximately a $90^{\circ}$ phase difference between high- and low-energy projections necessitates the image-space domain.

The projection-based material decomposition algorithm assumes that any attenuation coefficient can be described as a linear combination of the mass attenuation coefficient of two basis materials (4). The imaged-based algorithm expresses linear attenuation coefficients from high- and low-energy data as a linear combination of the mass attenuation coefficients of the two basis materials (3). VMI has the potential to improve the quality of conventional polychromatic CT images and provide quantitative measurements (5).

\section{Artifact and Noise Reduction}

VMI may improve image quality by decreasing metal or beam-hardening artifacts (5). However, the suitable energy level of VMI for each situation is different. Gyobu et al. (6) reported that metallic artifact significantly decreased in VMI at $100 \mathrm{keV}$ or $140 \mathrm{keV}$ and that VMI improved the detection of pulmonary nodules in a thoracic phantom study. Liu et al. (7) reported that VMI at $74 \mathrm{keV}$ with a metal artifact reduction algorithm could improve image quality for the micro-coil localization of pulmonary nodules. VMI also reduced beam-hardening artifact due to contrast media and improved image quality, and the optimal thoracic $\mathrm{CT}$ evaluation was best achieved at 100 keV and $130 \mathrm{keV}$ (Fig. 1) (8).

In addition, VMI provides for improved visualization

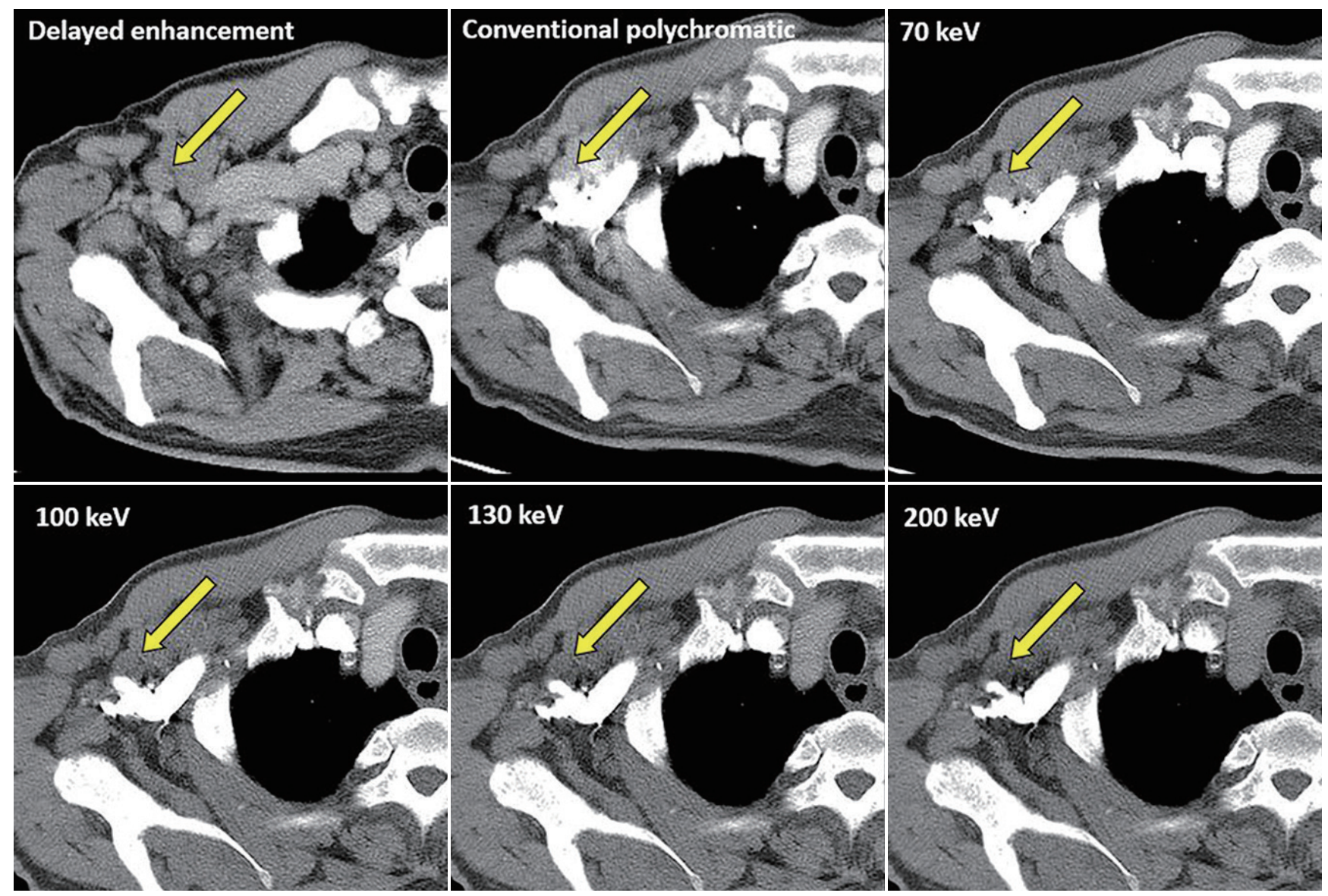

Fig. 1. Example of VMI for artifact reduction. Chest CT of delayed enhancement, conventional polychromatic images, and VMI at energy levels of 70, 100, 130, and $200 \mathrm{keV}$ in 70-year-old male with diffuse large B cell lymphoma. Enlarged lymph node involved by lymphoma is shown in right axillary area (arrows). On conventional polychromatic image, it is difficult to evaluate right axillary lymph node because of beamhardening artifact caused by contrast medium in right subclavian vein. However, $100 \mathrm{keV}$ and $130 \mathrm{keV}$ VMI reduced beam-hardening artifact such that lymph node can be assessed. VMI = virtual monoenergetic or monochromatic imaging 
of soft tissue lesions by decreasing image noise and increasing the signal-to-noise ratio and contrast-to-noise ratio. Two recent studies demonstrated that VMI at $60 \mathrm{keV}$ or $70 \mathrm{keV}$ provided the best combination of subjective and objective image quality in the evaluation of lung cancer $(9,10)$.

The results of these studies indicate that the most suitable energy level for each situation is different. Therefore, the energy level should be adjusted to control for the artifact or when evaluating lung nodules on CT scans. It is worth researching the best energy level for specific situations to streamline image reconstruction for each software. Alternatively, if radiologists prefer to upload VMI reconstructions to a picture archiving and communication system (PACS), the target energy level can be preset based on such studies.

\section{Contrast Enhancement}

The detection of hilar lymph nodes (LNs) is sometimes difficult when the enhancement of the pulmonary vessel is almost the same as that of the LN. However, VMI with low energy increased detectability, visibility, and correct measurement of the LNs can improve the accuracy of diagnosing LN metastasis. This is because VMI with low energy provides increased contrast enhancement of the pulmonary vessels even if the scan is not performed during the early enhancement phase (Fig. 2) (11, 12). A recent study proved that VMI at $40 \mathrm{keV}$ performed at a delayed phase (60 seconds after contrast media administration) was useful for the evaluation of hilar LNs, showing the greatest contrast differences between the pulmonary vessels and LNs (13).

Yue et al. (14) used VMI for the detection of inconspicuous osteoblastic metastases of the vertebra from lung cancer. They suggested that VMI at $70 \mathrm{keV}$ could be the best for diagnosing inconspicuous vertebral metastases, which have a similar density and are therefore not distinguishable from normal vertebrae (Fig. 3) (14).

However, there was a correlation between attenuation and volume changes at different energy levels of VMI (15). VMI with high energy resulted in low attenuation and nodule volumes, while VMI with low energy resulted in higher attenuation and nodule volumes. This is probably caused by differences in the peripheral enhancement of nodules at different energy levels, making an enlargement or reduction, and leading to the over- or under-estimation of nodule volumes. Therefore, attention should be paid to the possibility of over- or under-estimation when attempting to

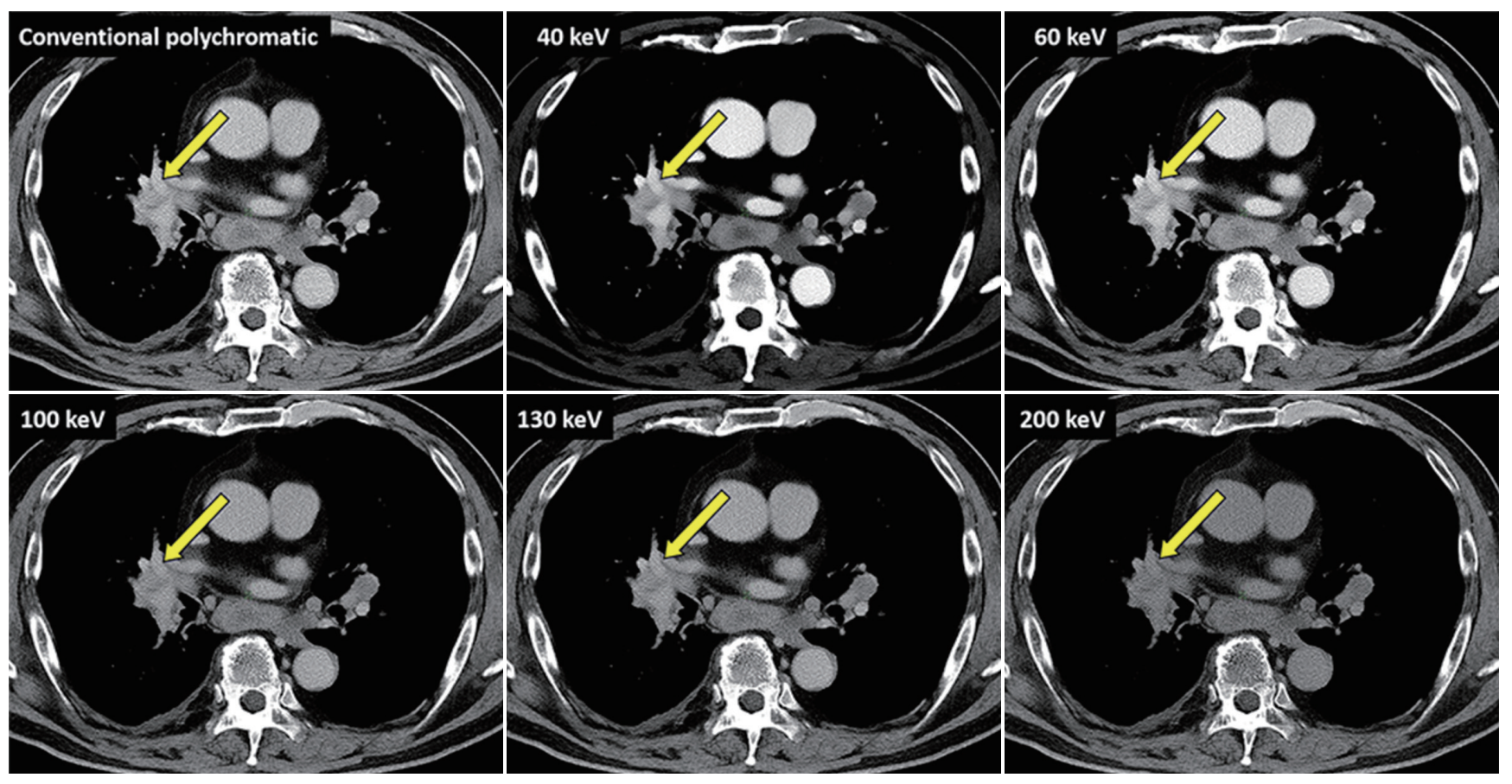

Fig. 2. Example of VMI for evaluation of lymph node metastasis. Chest CT images from 71-year-old male with lung cancer with mediastinal and bilateral hilar/interlobar lymph node metastases. In conventional polychromatic image, right interlobar lymph node detection is difficult because enhancement of pulmonary vessel is almost same as that of lymph node (arrows). However, VMI with 40 keV increased detectability and visibility of right interlobar lymph node. 
measure nodule volume using VMI.

\section{VNC}

The DESCT technique allows for the acquisition of data at different kilovoltage settings and makes it possible to differentiate iodine from other materials. This technique enables the subtraction of the iodine content in contrastenhanced DESCT, resulting in VNC. CT numbers of VNC were similar to true non-enhanced imaging (TNC) in a previous study (16). Therefore, VNC may easily detect calcifications or strongly attenuating nodes without additional TNC scanning, which results in reduced radiation exposure for the patient.

\section{Evaluation of Mediastinal LNs}

Although VNC may easily detect calcifications or strongly attenuating nodes without additional TNC scanning

(Fig. 4), the quantification of calcium in VNC may have
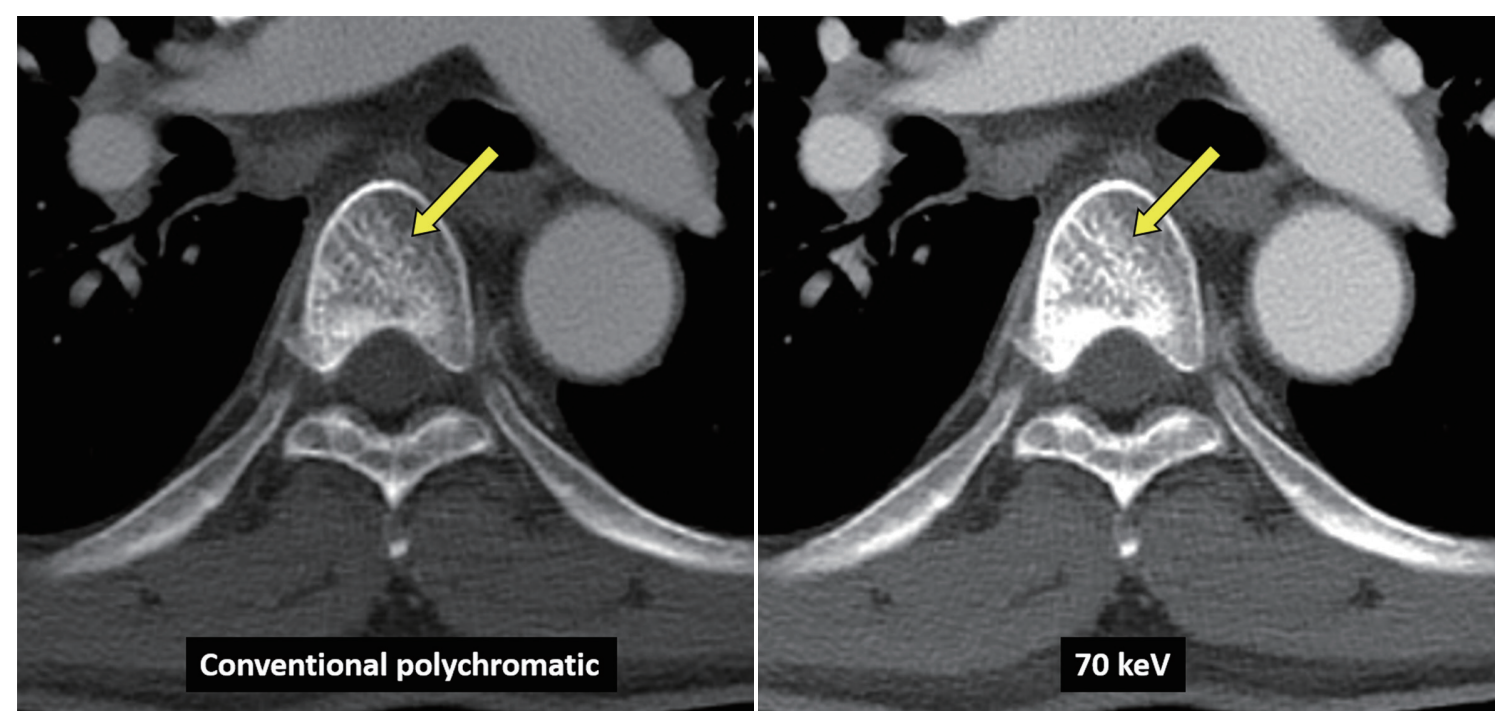

Fig. 3. Example of VMI for evaluation of bone metastasis. Chest CT images from 62-year-old male with lung cancer and bone metastases. Osteoblastic lesion at T6 vertebral body suggestive of bone metastasis is more detectable on VMI with 70 keV than on conventional polychromatic images (arrows).
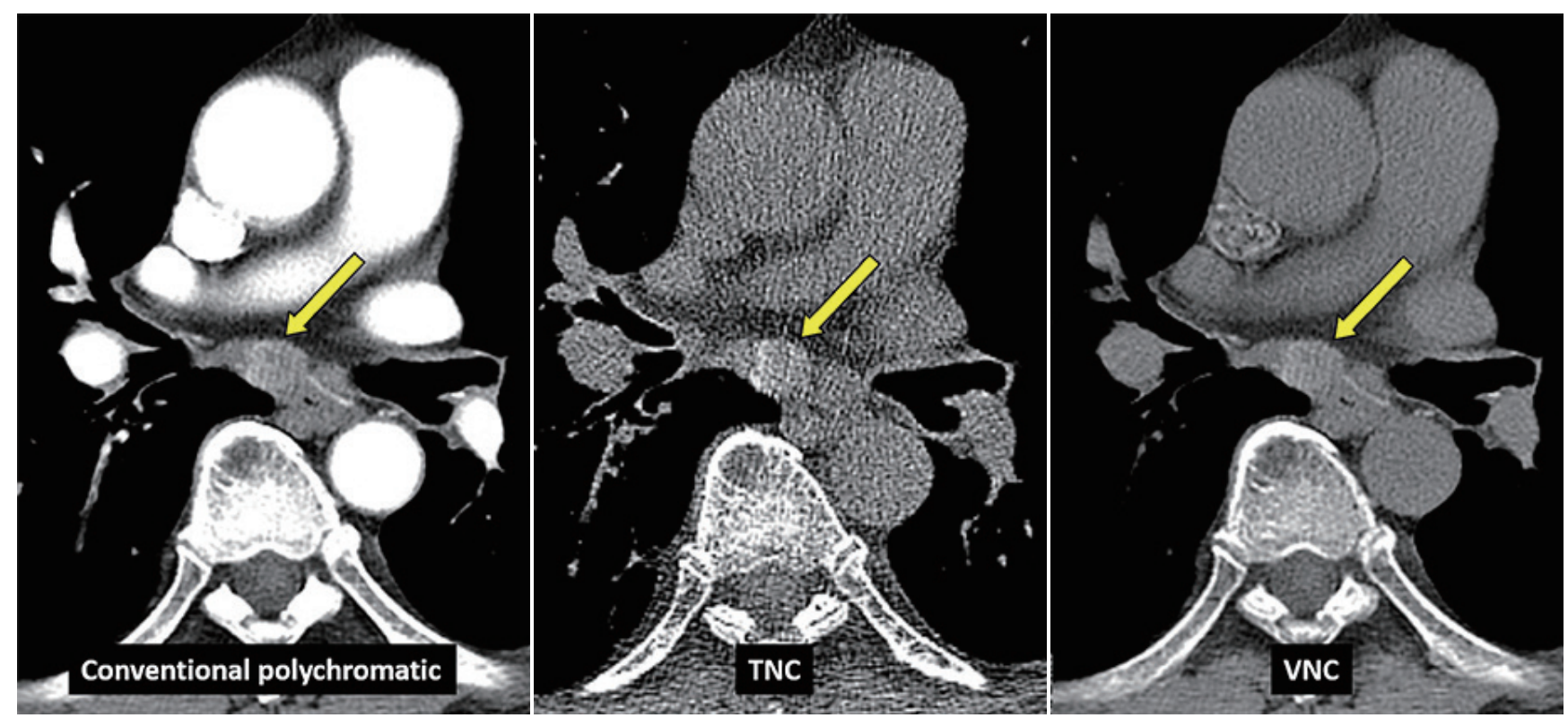

Fig. 4. Example of virtual non-calcium reconstruction for evaluation of mediastinal lymph nodes (arrows). Chest CT images of conventional polychromatic image, TNC, and VNC show calcified lymph node in subcarinal area of 42-year-old male. CT number of calcified lymph nodes in VNC $(94 \mathrm{HU})$ was similar to that of TNC $(89 \mathrm{HU})$. $\mathrm{HU}=$ Hounsfield unit, TNC $=$ true non-enhanced imaging, VNC $=$ virtual non-contrast or unenhanced imaging 
limitations. In a previous study, a moderate agreement was obtained between TNC and VNC in the evaluation of the CT attenuation of mediastinal LNs (intraclass correlation coefficient, 0.612) (17). In addition, there was an underestimation of high $\mathrm{CT}$ attenuation or calcification of the LNs in VNC compared to TNC. Another study by Chae et al. (16) also reported an underestimation of calcification in solitary pulmonary nodules (SPNs) or mediastinal LNs in VNC compared to TNC. These results could be due to partial subtraction of the calcium signal due to larger differences in photoelectric absorption compared to soft tissue, which results in a post-processing subtraction error.

\section{Evaluation of Intratumoral Hemorrhage}

Intratumoral hemorrhage or necrosis can develop during tumor treatment. It is challenging to evaluate tumor response in intratumoral hemorrhage or necrosis cases. Therefore, it is important to measure the real enhancement of the tumor. Intratumoral hemorrhage might lead to the overestimation of tumor diameters and may be regarded as an enhancing solid component, when only enhanced CT images are obtained. However, using VNC, intratumoral hemorrhage can be detected in patients with non-small cell lung cancer (NSCLC) treated with anti-angiogenic agents (18). Kim et al. (18) reported that intratumoral hemorrhage was detected in 14\% (4 of 29) of all tumors in VNC (Fig. 5). Furthermore, DESCT provided information on the real enhancement of target lesions without obtaining TNC.

\section{Virtual Non-Calcium Reconstruction for Diagnosing Vertebral Metastasis}

Abdullayev et al. (19) evaluated the diagnostic accuracy and visualization of vertebral metastasis using virtual noncalcium reconstructions. They used a prototype image recomposition algorithm that allows for the reconstruction of virtual non-calcium images based on spectral base images (SBI). Virtual non-calcium reconstruction images effectively suppressed calcium in multi-level vertebra by replacing the Hounsfield unit (HU) of voxels containing calcium with a virtual $\mathrm{HU}$ value as similar as possible to the expected $\mathrm{HU}$ without the calcium contribution. They found that virtual non-calcium reconstruction improved the diagnostic performance of metastasis detection (Fig. 6).

\section{Evaluation of Adrenal Masses}

In the evaluation of adrenal metastasis of lung cancer, VNC identified adrenal adenomas with $91 \%$ sensitivity and $100 \%$ specificity based on their typical imaging features (non-contrast attenuation < $10 \mathrm{HU}$ ) (Fig. 7) (20).

\section{Iodine Concentration Measurement}

Several DESCT parameters can be derived from iodine concentration measurements, and spectral curves can be obtained in both the arterial phase (AP) and venous phase (VP) or only a single-phase (Table 2). The slope rate of the spectral $\mathrm{HU}$ curve $(\lambda \mathrm{HU}), \mathrm{IC}$, and normalized iodine
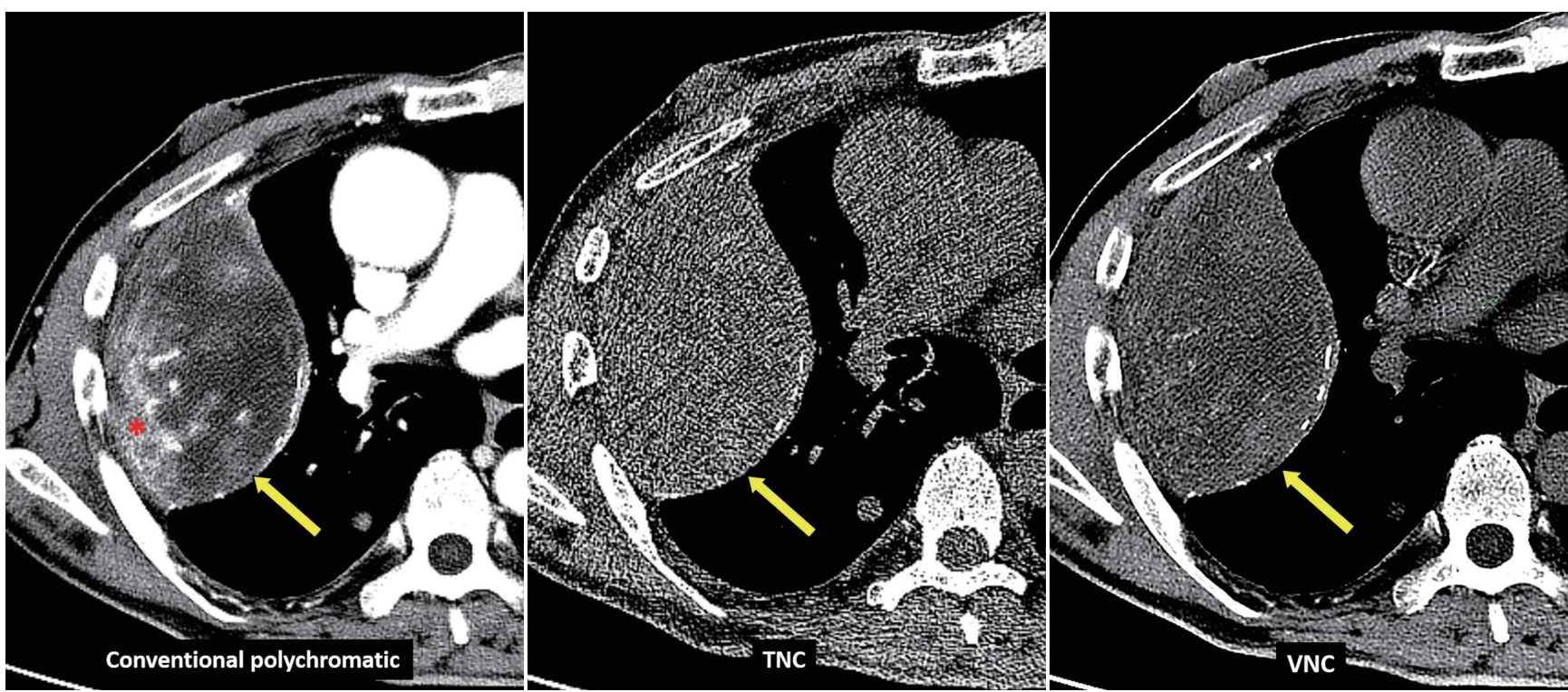

Fig. 5. Example of virtual non-calcium reconstruction for evaluation of intratumoral hemorrhage. Chest CT images of enhanced conventional polychromatic image, TNC, and VNC from 52-year-old male with sarcoma derived from chronic empyema. Intratumoral hemorrhage was detected in TNC and VNC (arrows). VNC also provided information on real enhancement of target lesions (asterisk). 

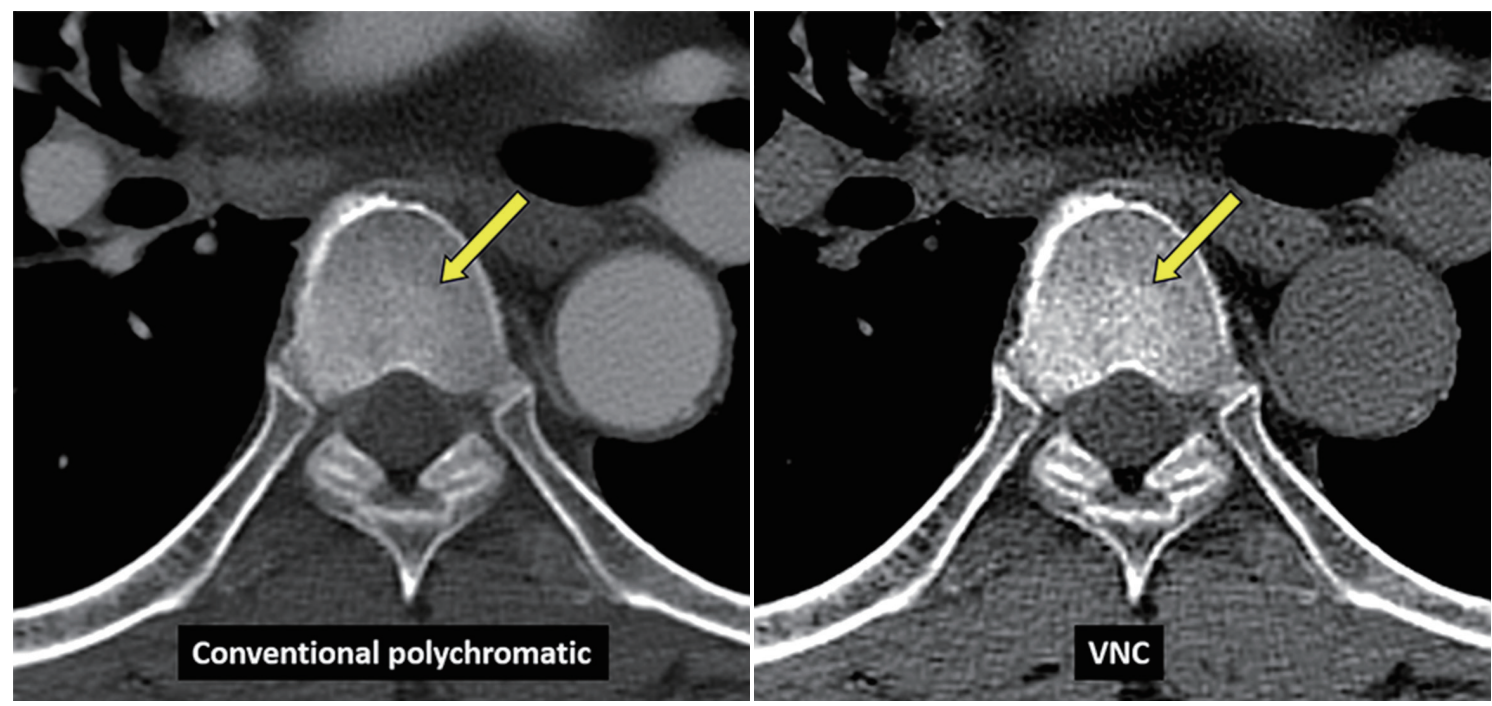

Fig. 6. Example of VNC for diagnosing vertebral metastasis. Chest CT images from 63-year-old male with lung cancer and bone metastases. Osteoblastic lesion at T8 vertebral body, which is suggestive of bone metastasis is more detectable on VNC than on conventional polychromatic image (arrows).

concentration (NIC) varied slightly from study to study (21), but the basic concept is similar.

As DESCT parameters have been associated with IC measurement and reflected microvessel density and blood supply in previous studies $(22,23)$, IC measurements in dual-energy CT could serve as a biomarker of tumor vascularity and help to correctly measure the degree of pulmonary nodule enhancement $(16,24)$. Additionally, changes in iodine content could reflect a response to chemotherapy or radiation.

\section{Malignant vs. Benign Lesions}

Several studies showed significant differences in IC on DESCT parameters between malignant and benign lesions (Fig. 8). Lin et al. (21) compared DESCT parameters between SPNs of inflammation, malignancies, and tuberculosis. The $\lambda \mathrm{HU}$, IC, and NIC of inflammatory SPNs were significantly higher than those of malignant SPNs were, and those of malignant SPNs were significantly higher than those of tuberculosis were. Similarly, Xiao et al. (25) reported that IC and NIC in both the AP and VP of malignant SPNs were significantly higher than those of benign SPNs were. Wu et al. (26) showed NICs according to different spatial distributions could differentiate malignant SPNs from benign SPNs. Chen et al. (27) also showed IC, NIC, $\lambda H U$, and VMI on $40 \mathrm{keV}$ and 70 $\mathrm{keV}$ images at both AP and VP are more promising methods for distinguishing malignant from benign SPNs.

However, several studies showed contradictory results to those discussed above. Results from Wang et al.'s study
(28) showed significantly greater IC, $\lambda \mathrm{HU}$, and $\mathrm{CT}$ values at $40 \mathrm{keV}$ in pneumonia than those in malignant tumors. Hou et al. (29) reported that inflammatory masses showed significantly higher $\lambda \mathrm{HU}$ at AP and VP than malignant masses. Patients with inflammatory myofibroblastic tumors had significantly higher NIC and $\lambda \mathrm{HU}$ at both AP and VP and IC differences between AP and VP than patients with lung cancer did (30). These results may be due to inappropriate angiogenesis resulting in abnormal vascular networks in lung cancer, which could cause tumor hypoxia and necrosis, leading to inhomogeneous enhancement on CT. However, further studies are needed to clarify these findings further.

There are also several studies about iodine content in DESCT related to $L N$ metastases from lung cancers. $L N$ metastases showed lower IC than benign LNs, which was statistically significant (20). $\lambda \mathrm{HU}$ at both AP and VP were significantly higher in LN metastasis than in benign LNs, suggesting rapid washout of contrast media in metastatic LNs (31). Besides, several studies evaluated the correlation of iodine content with the diameters of LNs or lung cancer. Fehrenbach et al. (20) reported that enlarged LNs showed significantly lower IC and $\lambda \mathrm{HU}$ than normal-sized nodes. Significant differences in IC, NIC, and $\lambda \mathrm{HU}$ were observed between different LN diameters (normal: $<10 \mathrm{~mm}$; intermediate: $\geq 10 \mathrm{~mm}$ to $<15 \mathrm{~mm}$; enlarged: $\geq 15 \mathrm{~mm}$ ). Aoki et al. (32) reported that the average iodine density was significantly lower in larger lung cancers. The authors believe that the development of hypoxia is related to the size of the tumor. 
Differentiation of Tumors, Subtypes, Pathologic Grades, and Molecular Subcategories of Lung Cancer

There were significant differences in the DESCT parameters according to histologic subtypes and pathologic grades of lung cancer. Jia et al. (23) found that DESCT parameters
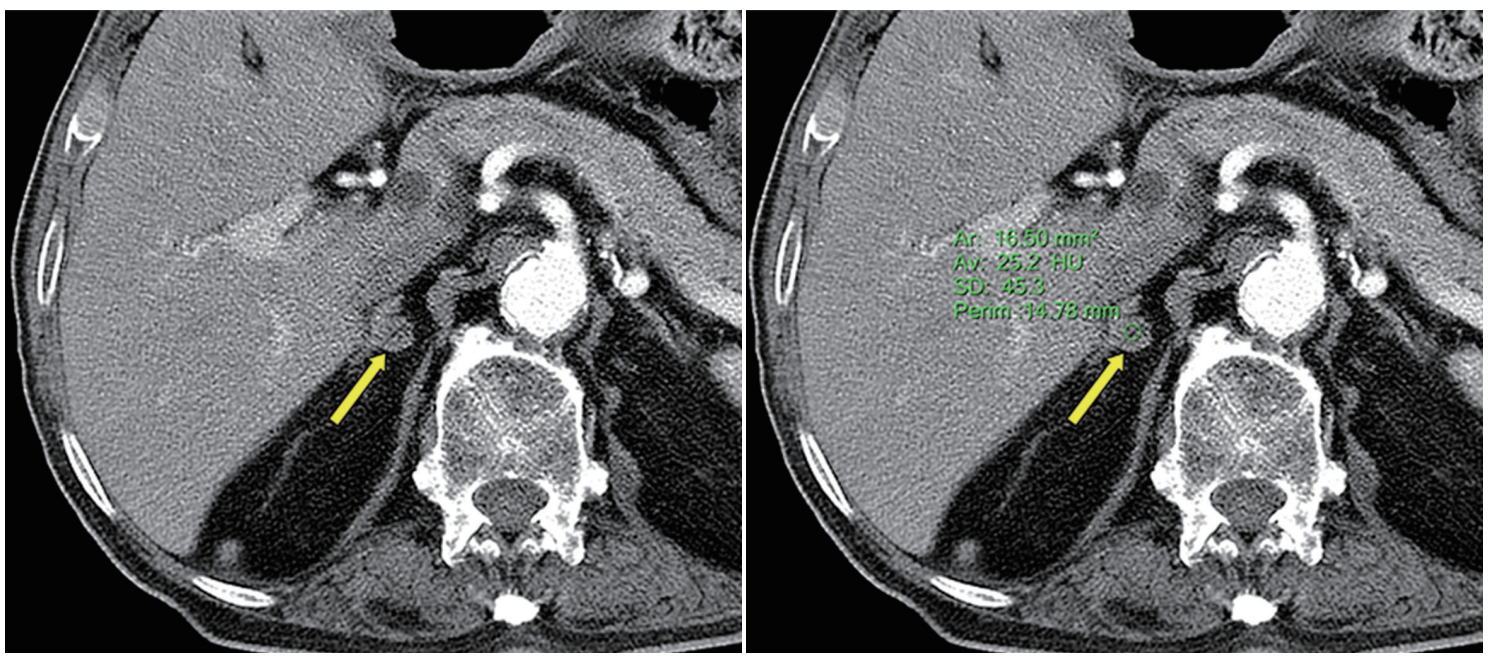

A
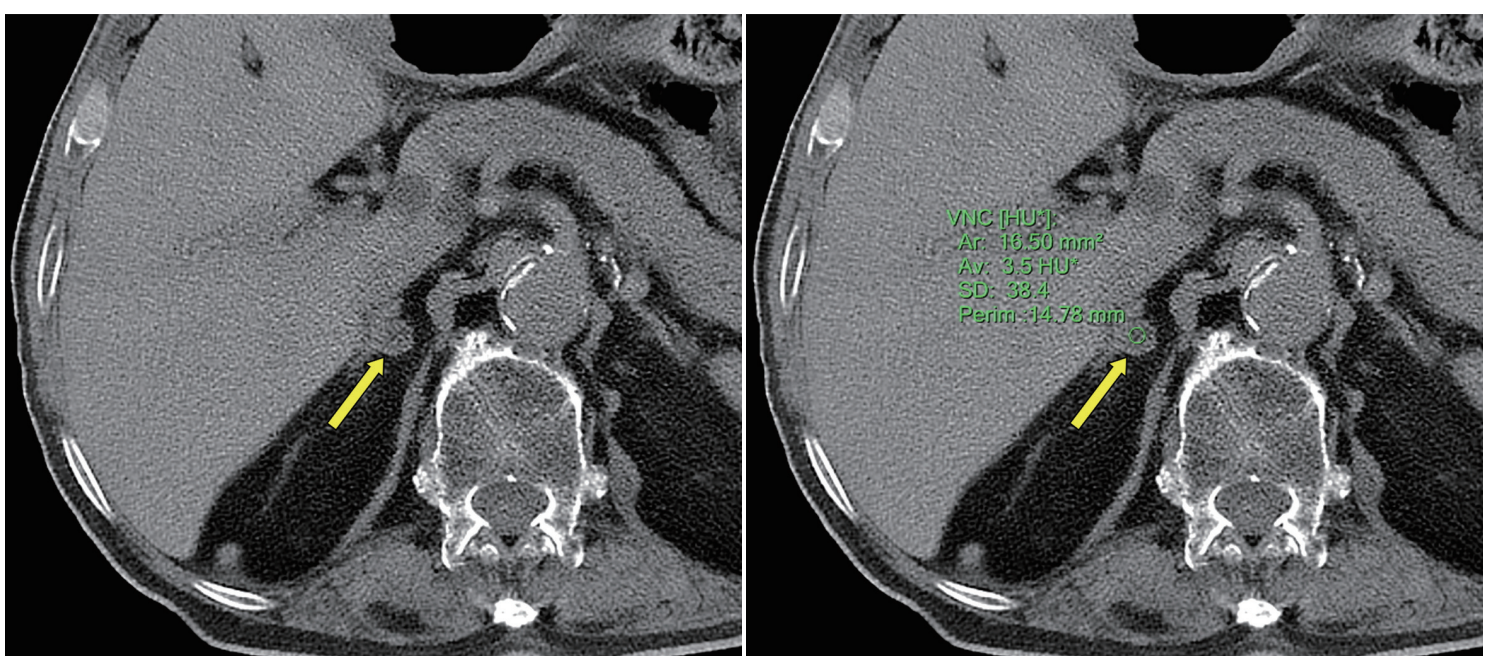

B

Fig. 7. Example of VNC in evaluation of adrenal masses. Chest CT images from 57-year-old female with lung cancer with adenoma in right adrenal gland (arrows).

A. In conventional polychromatic image, right adrenal adenoma shows mild contrast enhancement (left). CT number of right adrenal adenoma is 25.2 HU (right). B. In VNC, mild enhancement of right adrenal adenoma is not shown (left), and CT number is $3.5 \mathrm{HU}$ (right).

Table 2. Several DESCT Parameters Derived from IC Measurements and Their Definitions

\begin{tabular}{lcc}
\hline \multicolumn{1}{c}{ Parameters } & Abbreviations (Unit) & Definition \\
$\begin{array}{l}\text { Slope rate (or pitch) of spectral } \\
\mathrm{HU} \text { curve }\end{array}$ & $\lambda \mathrm{HU}$ & $\begin{array}{c}\text { Difference in CT values at } 40 \mathrm{keV} \text { and } 100 \mathrm{keV} \text { divided by } 60 \text { or at } 40 \mathrm{keV} \\
\text { and } 120 \mathrm{keV} \text { divided by } 80\end{array}$ \\
$\begin{array}{l}\text { Iodine concentration } \\
\text { IC }(\mathrm{mg} / \mathrm{mL})\end{array}$ & $\begin{array}{c}\text { Iodine content per unit volume (mL), measured at iodine-based material } \\
\text { decomposition imaging }\end{array}$ \\
$\begin{array}{l}\text { Normalized iodine concentration } \\
\text { Normalized to IC in aorta to minimize variation in patients, scanning } \\
\text { times, and ICs: NIC = ICL/ICA }\end{array}$ \\
\hline
\end{tabular}

ICA = IC in aorta, ICL = IC in lesion 
overall, iodine values were higher in adenocarcinoma

than in squamous cell carcinoma $(20,28)$. Lin et al. (33) reported that NIC and $\lambda \mathrm{HU}$ at both AP and VP in low-grade NSCLC were significantly higher than those in high-grade NSCLC were.

Several studies revealed a significant negative correlation between DESCT parameters and pathological grades of NSCLC. IC, $\lambda \mathrm{HU}$, and VMI at $40 \mathrm{keV}$ showed a significant positive correlation with the level of vascular endothelial growth factor (VEGF) expression in NSCLC, proving the association between DESCT parameters and tumor angiogenesis (34). Li et al. (35) suggested that NIC
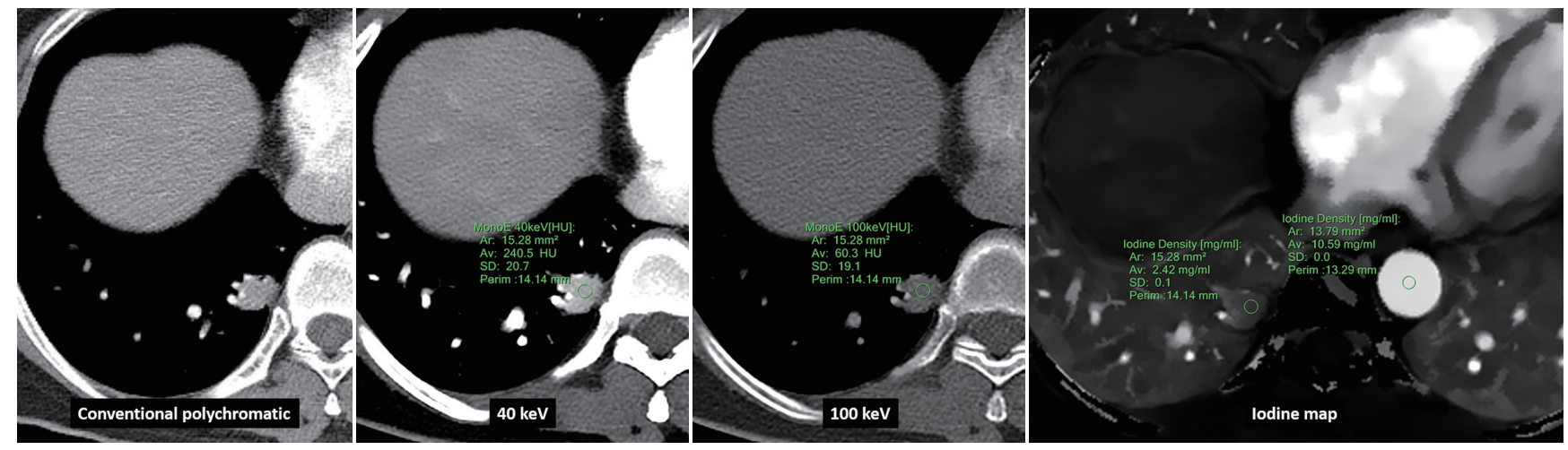

A
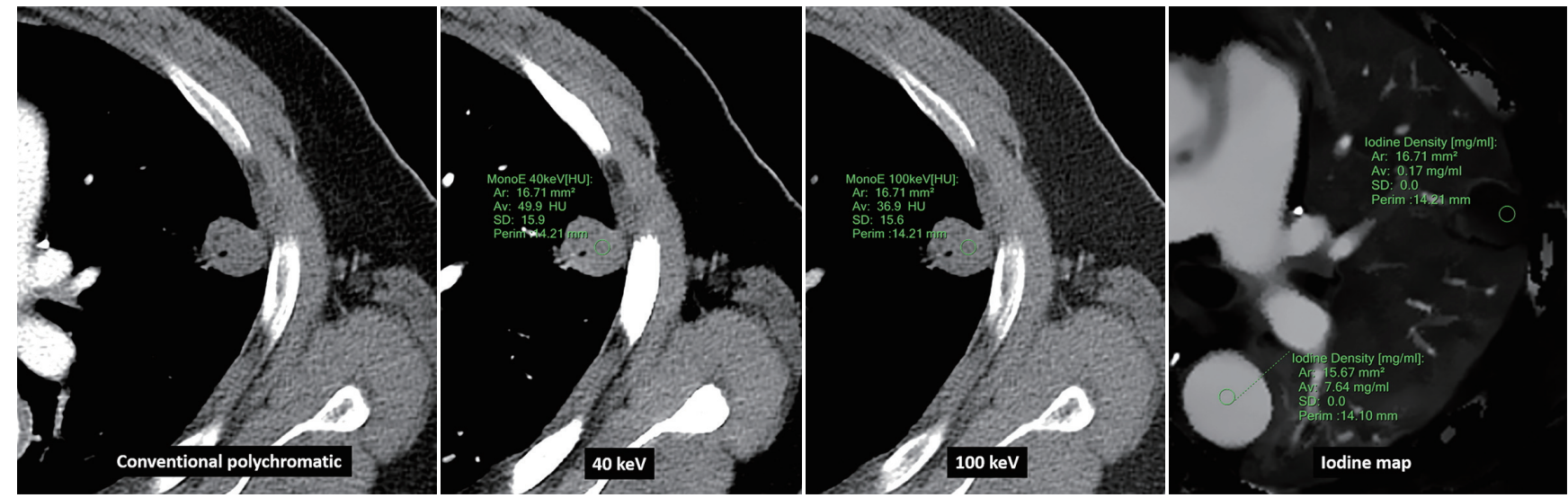

B
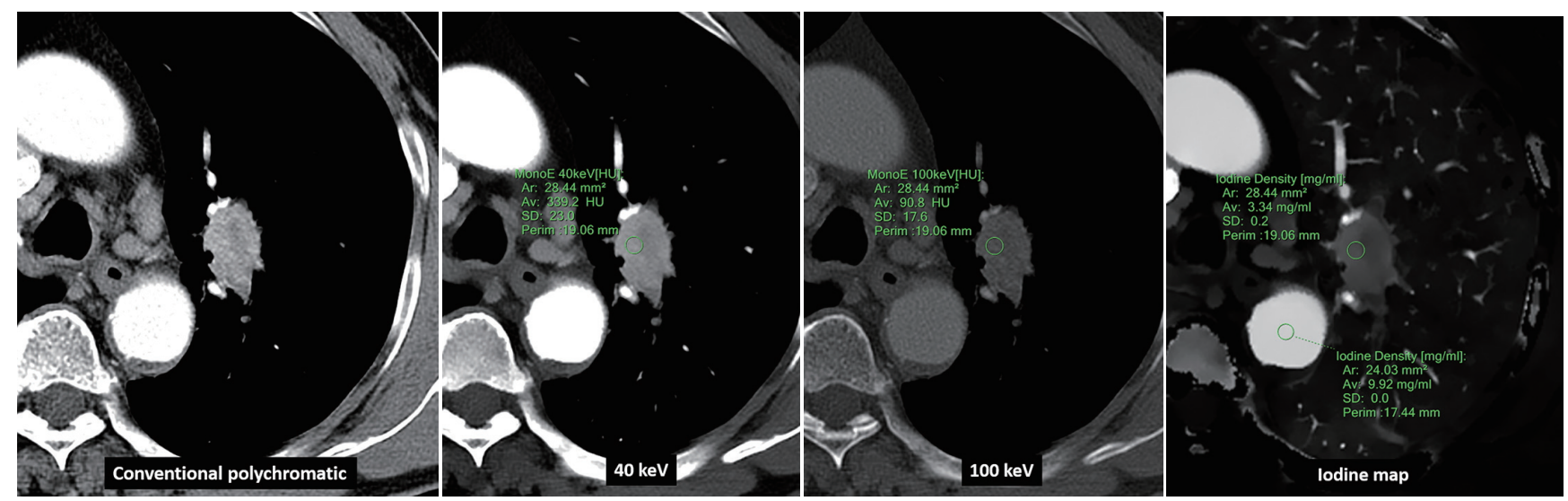

Fig. 8. Examples showing differences in IC of DESCT parameters between malignant and benign lesions.

CT images of enhanced conventional polychromatic, VMI at $40 \mathrm{keV}$ and $100 \mathrm{keV}$, and iodine maps show different IC on DESCT parameters of (A) adenocarcinoma ( $\lambda \mathrm{HU}, 3 ; \mathrm{IC}, 2.42 \mathrm{mg} / \mathrm{mL}$; NIC; 0.229), (B) pulmonary tuberculosis $(\lambda \mathrm{HU}, 0.217 ; \mathrm{IC}, 0.17 \mathrm{mg} / \mathrm{mL} ; \mathrm{NIC} ; 0.022)$, and (C) squamous cell carcinoma $(\lambda \mathrm{HU}, 4.14 ; \mathrm{IC}, 3.34 \mathrm{mg} / \mathrm{mL}$; NIC; 0.337$)$. DESCT = dual-energy spectral computed tomography, IC $=$ iodine concentration, NIC = normalized iodine concentration, $\lambda \mathrm{HU}=$ slope rate of spectral $\mathrm{HU}$ curve 
might be a potential predictive quantitative parameter for the identification of epidermal growth factor receptor (EGFR) mutations in patients with adenocarcinoma. Their multivariate analysis revealed that smoking history and NIC were significant predictors of EGFR mutations in adenocarcinoma. The combination of these two significant predictive factors had moderate predictive value for identifying EGFR mutations in adenocarcinomas. Liu et al. (36) showed that there were significant differences in NICs between pure ground-glass nodules (GGN) and mixed GGN, and suggested that DESCT parameters could be an indicator of the blood supply status in GGN.

In addition, iodine content from DESCT could help to differentiate pulmonary metastases from different primary origins. Deniffel et al. (37) demonstrated significant differences in the IC and CT numbers in pulmonary metastases of renal cell carcinoma versus breast, colorectal, and head/neck carcinoma as well as metastases of colorectal carcinoma versus osteosarcoma, pancreato-biliary, and urinary tract carcinoma. They provided a reference range of the quantitative IC values derived from DESCT for these pulmonary metastases.

Iodine quantification with DESCT was also useful for differentiating low-risk thymomas from other thymic tumors. Yan et al. (38) demonstrated that the iodine content of low-risk thymomas measured in DESCT was significantly higher than that of high-risk thymomas, thymic carcinomas, and thymic lymphoma were.

Treatment Response Evaluation with/without Correlation with Positron Emission Tomography-CT

Several studies tried to validate the potential contribution of DESCT parameters in evaluating the therapeutic effects in lung cancers or mediastinal LNs. In a retrospective study by Baxa et al. (39), the mean values of IC in both AP and VP before and after chemotherapy increased in the non-responding LNs and decreased in the LNs with a response. Liu et al. (40) evaluated therapeutic effects after radiofrequency ablation (RFA) of lung tumors using DESCT parameters. The iodine content significantly decreased after RFA, reflecting the metabolic state of the tumors. Izaaryene et al. (41) reported that iodine content predicted early recurrence of primary or secondary lung tumors after RFA and suggested a threshold between $20 \mathrm{HU}$ and 35 HU. Fehrenbach et al. (42) also demonstrated that DESCT parameters of NSCLC after chemoradiotherapy might help in predicting recurrence. In their study, NSCLC with progressive disease (PD) showed significantly higher IC than tumors in patients with stable disease (SD) or partial response. Patients with PD during follow-up (FU) had significantly higher IC on the initial DESCT scan than those with SD during FU. The IC difference (IC at hotspot analysis - IC) and NIC difference (NIC at hotspot analysis - NIC) was significantly different between $\mathrm{PD}, \mathrm{PD}$ during $\mathrm{FU}$, and $\mathrm{SD}$ during FU.

The correlation between DESCT parameters and metabolic uptake in ${ }^{18} \mathrm{~F}$-fluorodeoxyglucose positron emission tomography (PET-CT) and association with tumor recurrence were also evaluated in several studies. Aoki et al. $(43,44)$ found strong correlations between IC and the maximum standardized uptake value $\left(\mathrm{SUV}_{\max }\right)$ on PET-CT with local recurrence in NSCLC treated with stereotactic body radiotherapy (SBRT). Tumors with a lower IC and higher SUV $V_{\text {max }}$ showed significantly higher local recurrence rates, demonstrating an association of radioresistance with low tumor blood volume and a probable association with hypoxia. According to Ren et al. (45), the strong association between DESCT parameters and PET-CT was also found in primary or metastatic lung tumors, and both pre- and post-treatment with radiotherapy or chemoradiotherapy.

\section{Parenchymal Perfusion Defects due to Central Lung}

Cancers or Pulmonary Thromboembolism

Pulmonary perfusion defects induced by central lung cancer could be easily detected by IC (46). Perfusion defects caused by pulmonary thromboembolism, which can develop with lung cancer or in the course of lung cancer treatment could be identified and quantified by a significant decrease in IC in the affected areas compared to the surrounding lung tissue (Fig. 9) (20).

\section{Effective Atomic Number ( $Z_{\text {eff }}$ map)}

$Z_{\text {eff }}$ is a quantitative index that represents the composite atom for a compound or mixture of various materials, which can be calculated from DESCT data with a small error rate $(4.1 \% \pm 0.3 \%)(47)$. Regardless of $X$-ray energy, the CT number of water is zero, and the $Z_{\text {eff }}$ of water is about 7.4-7.5 (2).

As the clinical significance of $Z_{\text {eff }}$ is unclear, $Z_{\text {eff }}$ has not been well studied in the field of thoracic oncology. Only a few studies on this topic have been published. Significantly greater $Z_{\text {eff }}$ was measured in benign thyroid nodules than 


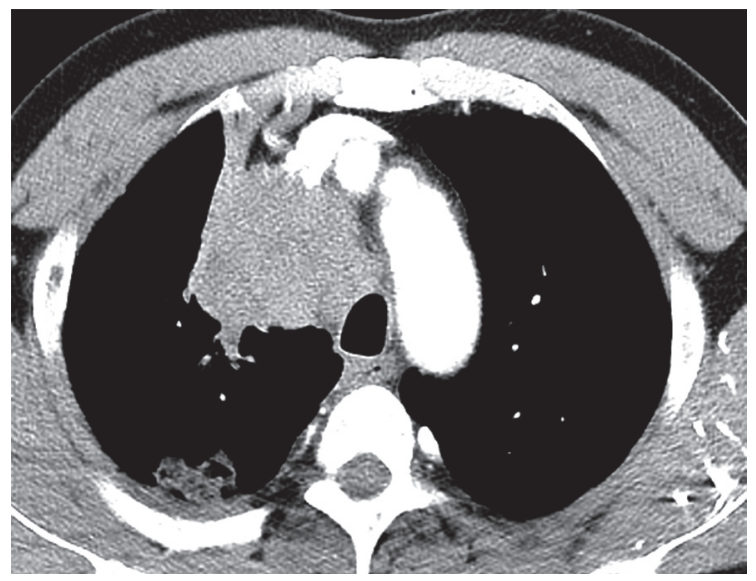

A

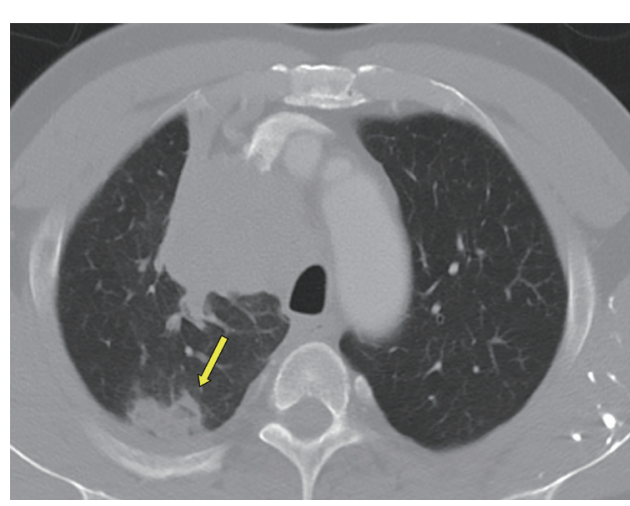

C

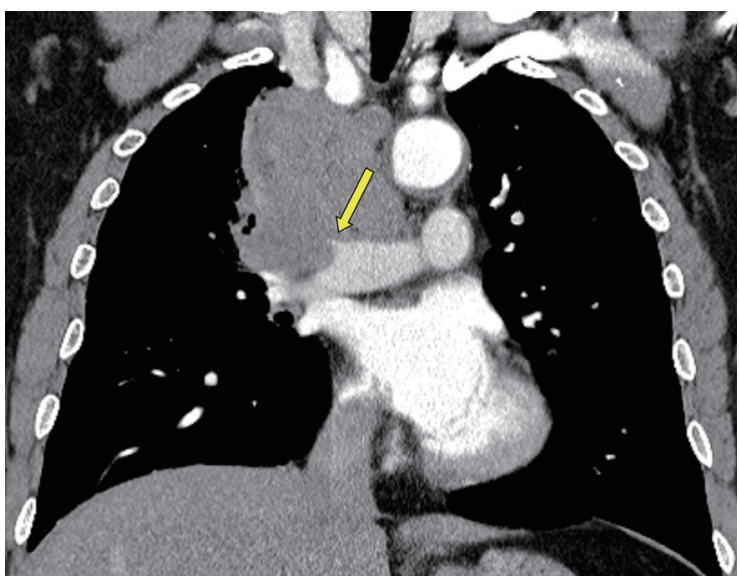

B

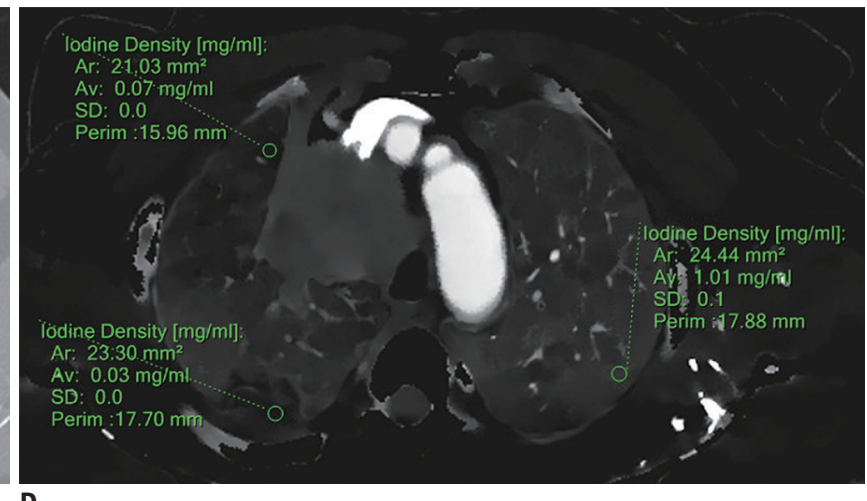

Fig. 9. Example showing differences in IC of pulmonary perfusion defects induced by central lung cancer.

A. Enhanced chest CT axial image shows $7 \mathrm{~cm}$ well-enhanced mass proven to be adenocarcinoma from 68-year-old male. B. Coronal image shows total obstruction of pulmonary artery of RUL (arrow). C. Axial image with lung window setting shows patchy consolidation in RUL, which is suggestive of lung infarction (arrow). D. IC map showing decreased IC in right middle lobe $(0.07$ and $0.03 \mathrm{mg} / \mathrm{mL}$ ), which is suggestive of decreased lung perfusion, compared to that of contralateral lung $(1.01 \mathrm{mg} / \mathrm{mL})$. RUL = right upper lobe

in papillary carcinomas (48), and higher $Z_{\text {eff }}$ was exhibited in soft-tissue sarcomas than in normal tissues (49). For lung tumors, a lower minimum $Z_{\text {eff }}$ and normalized mean $Z_{\text {eff }}$ statistically correlated with malignant lung tumors (47). $Z_{\text {eff }}$ at both AP and VP were significantly different between squamous cell cancer, adenocarcinoma, and neuroendocrine tumors (23).

\section{CONCLUSION}

The technical aspects of DESCT have rapidly developed in recent years, and much research has been done on the application of DESCT in thoracic oncology. However, further research is still required. The DESCT parameter values are not uniform across studies, and $Z_{\text {eff }}$ has not been well studied in relation to the thoracic oncology field. If the potential advantages of the DESCT technique can be used in the field of thoracic oncology, we believe that significant advances will be made in appropriate early diagnoses, assessing tumor response, and prognostic assessment.

\section{Conflicts of Interest}

The authors have no potential conflicts of interest to disclose.

ORCID iDs

Ki Yeol Lee

https://orcid.org/0000-0002-0323-1280

Cherry Kim

https://orcid.org/0000-0002-3361-5496

Wooil Kim

https://orcid.org/0000-0002-9743-7449

Sung-Joon Park

https://orcid.org/0000-0002-1187-7671

Young Hen Lee

https://orcid.org/0000-0001-7739-4173 


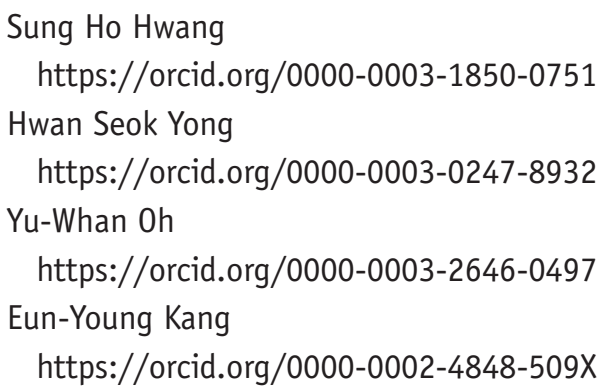

\section{REFERENCES}

1. Hounsfield GN. Computerized transverse axial scanning (tomography): part 1. Description of system. Br J Radiol 1973; 46:1016-1022

2. Goo HW, Goo JM. Dual-energy CT: new horizon in medical imaging. Korean J Radiol 2017;18:555-569

3. Mileto A, Barina A, Marin D, Stinnett SS, Roy Choudhury $K$, Wilson JM, et al. Virtual monochromatic images from dual-energy multidetector CT: variance in CT numbers from the same lesion between single-source projection-based and dual-source image-based implementations. Radiology 2016;279:269-277

4. Garcia LI, Azorin JF, Almansa JF. A new method to measure electron density and effective atomic number using dualenergy CT images. Phys Med Biol 2016;61:265-279

5. Yu L, Leng S, McCollough CH. Dual-energy CT-based monochromatic imaging. AJR Am J Roentgenol 2012;199:S9S15

6. Gyobu T, Honda 0, Kawata Y, Kikuyama A, Miki H, Yanagawa $M$, et al. The effect of the virtual monochromatic spectral imaging for the metallic artifact and the pulmonary nodule detection. J Comput Assist Tomogr 2013;37:707-711

7. Liu Z, Zhang Z, Chen C, Hong N. Value of virtual monochromatic spectral images with metal artifact reduction algorithm in dual-energy computed tomography-guided microcoil localization of pulmonary nodules. Medicine (Baltimore) 2018;97:e11562

8. Kim C, Kim D, Lee KY, Kim H, Cha J, Choo JY, et al. The optimal energy level of virtual monochromatic images from spectral CT for reducing beam-hardening artifacts due to contrast media in the thorax. AJR Am J Roentgenol 2018;211:557-563

9. Kaup M, Scholtz JE, Engler A, Albrecht MH, Bauer RW, Kerl JM, et al. Dual-energy computed tomography virtual monoenergetic imaging of lung cancer: assessment of optimal energy levels. J Comput Assist Tomogr 2016;40:80-85

10. Hou W, Sun X, Yin Y, Cheng J, Zhang Q, Xu J, et al. Improving image quality for lung cancer imaging with optimal monochromatic energy level in dual energy spectral computed tomography. J Comput Assist Tomogr 2016;40:243-247

11. Petersilka M, Bruder H, Krauss B, Stierstorfer K, Flohr TG. Technical principles of dual source CT. Eur J Radiol
2008; 68:362-368

12. Thaiss WM, Sauter AW, Bongers M, Horger M, Nikolaou K. Clinical applications for dual energy $\mathrm{CT}$ versus dynamic contrast enhanced CT in oncology. Eur J Radiol 2015;84:2368-2379

13. Sekiguchi T, Ozawa Y, Hara M, Nakagawa M, Goto T, Shibamoto Y. Visibility of the hilar lymph nodes using advanced virtual monoenergetic low-keV images for preoperative evaluation of lung cancer. Br J Radiol 2019;92:20180734

14. Yue D, Ru Xin W, Jing C, Fan Rong C, Li Fei S, Ai Lian L, et al. Virtual monochromatic spectral imaging for the evaluation of vertebral inconspicuous osteoblastic metastases from lung. Acta Radiol 2017;58:1485-1492

15. den Harder AM, Bangert F, van Hamersvelt RW, Leiner T, Milles $J$, Schilham AMR, et al. The effects of iodine attenuation on pulmonary nodule volumetry using novel dual-layer computed tomography reconstructions. Eur Radiol 2017;27:5244-5251

16. Chae EJ, Song JW, Seo JB, Krauss B, Jang YM, Song KS. Clinical utility of dual-energy $\mathrm{CT}$ in the evaluation of solitary pulmonary nodules: initial experience. Radiology 2008;249:671-681

17. Yoo SY, Kim Y, Cho HH, Choi MJ, Shim SS, Lee JK, et al. Dualenergy CT in the assessment of mediastinal lymph nodes: comparative study of virtual non-contrast and true noncontrast images. Korean J Radiol 2013;14:532-539

18. Kim YN, Lee HY, Lee KS, Seo JB, Chung MJ, Ahn MJ, et al. Dual-energy $C T$ in patients treated with anti-angiogenic agents for non-small cell lung cancer: new method of monitoring tumor response? Korean J Radiol 2012;13:702-710

19. Abdullayev N, Große Hokamp N, Lennartz S, Holz JA, Romman $Z$, Pahn G, et al. Improvements of diagnostic accuracy and visualization of vertebral metastasis using multi-level virtual non-calcium reconstructions from dual-layer spectral detector computed tomography. Eur Radiol 2019;29:5941-5949

20. Fehrenbach U, Kahn J, Böning G, Feldhaus F, Merz K, Frost $\mathrm{N}$, et al. Spectral CT and its specific values in the staging of patients with non-small cell lung cancer: technical possibilities and clinical impact. Clin Radiol 2019;74:456-466

21. Lin JZ, Zhang L, Zhang CY, Yang L, Lou HN, Wang ZG. Application of gemstone spectral computed tomography imaging in the characterization of solitary pulmonary nodules: preliminary result. J Comput Assist Tomogr 2016;40:907-911

22. Wu F, Zhou H, Li F, Wang JT, Ai T. Spectral CT imaging of lung cancer: quantitative analysis of spectral parameters and their correlation with tumor characteristics. Acad Radiol 2018;25:1398-1404

23. Jia $Y$, Xiao X, Sun Q, Jiang H. CT spectral parameters and serum tumour markers to differentiate histological types of cancer histology. Clin Radiol 2018;73:1033-1040

24. Chen X, Xu Y, Duan J, Li C, Sun H, Wang W. Correlation of iodine uptake and perfusion parameters between dual-energy CT imaging and first-pass dual-input perfusion CT in lung cancer. Medicine (Baltimore) 2017;96:e7479

25. Xiao H, Liu Y, Tan H, Liang P, Wang B, Su L, et al. A pilot study using low-dose spectral CT and ASIR (adaptive 
statistical iterative reconstruction) algorithm to diagnose solitary pulmonary nodules. BMC Med Imaging 2015;15:54

26. Wu L, Cao G, Zhao L, Tang K, Lin J, Miao S, et al. Spectral $\mathrm{CT}$ analysis of solitary pulmonary nodules for differentiating malignancy from benignancy: the value of iodine concentration spatial distribution difference. Biomed Res Int 2018;2018:4830659

27. Chen ML, Li XT, Wei YY, Qi LP, Sun YS. Can spectral computed tomography imaging improve the differentiation between malignant and benign pulmonary lesions manifesting as solitary pure ground glass, mixed ground glass, and solid nodules? Thorac Cancer 2019;10:234-242

28. Wang G, Zhang C, Li M, Deng K, Li W. Preliminary application of high-definition computed tomographic Gemstone Spectral Imaging in lung cancer. J Comput Assist Tomogr 2014;38:7781

29. Hou WS, Wu HW, Yin Y, Cheng JJ, Zhang Q, Xu JR. Differentiation of lung cancers from inflammatory masses with dual-energy spectral CT imaging. Acad Radiol 2015;22:337344

30. Yu Y, Wang X, Shi C, Hu S, Zhu H, Hu C. Spectral computed tomography imaging in the differential diagnosis of lung cancer and inflammatory myofibroblastic tumor. J Comput Assist Tomogr 2019;43:338-344

31. Yang F, Dong J, Wang X, Fu X, Zhang T. Non-small cell lung cancer: spectral computed tomography quantitative parameters for preoperative diagnosis of metastatic lymph nodes. Eur J Radiol 2017;89:129-135

32. Aoki M, Takai Y, Narita Y, Hirose K, Sato M, Akimoto H, et al. Correlation between tumor size and blood volume in lung tumors: a prospective study on dual-energy gemstone spectral CT imaging. J Radiat Res 2014;55:917-923

33. Lin LY, Zhang Y, Suo ST, Zhang F, Cheng JJ, Wu HW. Correlation between dual-energy spectral CT imaging parameters and pathological grades of non-small cell lung cancer. Clin Radiol 2018;73:412.e1-412.e7

34. Li GJ, Gao J, Wang GL, Zhang CQ, Shi H, Deng K. Correlation between vascular endothelial growth factor and quantitative dual-energy spectral CT in non-small-cell lung cancer. Clin Radiol 2016;71:363-368

35. Li M, Zhang L, Tang W, Jin YJ, Qi LL, Wu N. Identification of epidermal growth factor receptor mutations in pulmonary adenocarcinoma using dual-energy spectral computed tomography. Eur Radiol 2019;29:2989-2997

36. Liu G, Li M, Li G, Li Z, Liu A, Pu R, et al. Assessing the blood supply status of the focal ground-glass opacity in lungs using spectral computed tomography. Korean J Radiol 2018;19:130138

37. Deniffel D, Sauter A, Dangelmaier J, Fingerle A, Rummeny EJ, Pfeiffer D. Differentiating intrapulmonary metastases from different primary tumors via quantitative dual-energy CT based iodine concentration and conventional CT attenuation. Eur J Radiol 2019;111:6-13

38. Yan WQ, Xin YK, Jing Y, Li GF, Wang SM, Rong WC, et al. Iodine quantification using dual-energy computed tomography for differentiating thymic tumors. J Comput Assist Tomogr 2018;42:873-880

39. Baxa J, Vondráková A, Matoušková T, Růžičková 0, Schmidt $B$, Flohr T, et al. Dual-phase dual-energy CT in patients with lung cancer: assessment of the additional value of iodine quantification in lymph node therapy response. Eur Radiol 2014;24:1981-1988

40. Liu L, Zhi X, Liu B, Zhang Y. Utilizing gemstone spectral CT imaging to evaluate the therapeutic efficacy of radiofrequency ablation in lung cancer. Radiol Med 2016;121:261-267

41. Izaaryene J, Vidal V, Bartoli JM, Loundou A, Gaubert JY. Role of dual-energy computed tomography in detecting early recurrences of lung tumours treated with radiofrequency ablation. Int J Hyperthermia 2017;33:653-658

42. Fehrenbach U, Feldhaus F, Kahn J, Böning G, Maurer MH, Renz D, et al. Tumour response in non-small-cell lung cancer patients treated with chemoradiotherapy-can spectral CT predict recurrence? J Med Imaging Radiat Oncol 2019;63:641649

43. Aoki M, Akimoto $H$, Sato M, Hirose K, Kawaguchi H, Hatayama $Y$, et al. Impact of pretreatment whole-tumor perfusion computed tomography and ${ }^{18} \mathrm{~F}$-fluorodeoxyglucose positron emission tomography/computed tomography measurements on local control of non-small cell lung cancer treated with stereotactic body radiotherapy. J Radiat Res 2016;57:533-540

44. Aoki M, Hirose K, Sato M, Akimoto H, Kawaguchi $H$, Hatayama $Y$, et al. Prognostic impact of average iodine density assessed by dual-energy spectral imaging for predicting lung tumor recurrence after stereotactic body radiotherapy. J Radiat Res 2016;57:381-386

45. Ren Y, Jiao Y, Ge W, Zhang L, Hua Y, Li C, et al. Dual-energy computed tomography-based iodine quantitation for response evaluation of lung cancers to chemoradiotherapy/radiotherapy: a comparison with fluorine-18 fluorodeoxyglucose positron emission tomography/computed tomography-based positron emission tomography/computed tomography response evaluation criterion in solid tumors. J Comput Assist Tomogr 2018;42:614-622

46. Sun YS, Zhang XY, Cui Y, Tang L, Li XT, Chen Y, et al. Spectral CT imaging as a new quantitative tool? Assessment of perfusion defects of pulmonary parenchyma in patients with lung cancer. Chin J Cancer Res 2013;25:722-728

47. González-Pérez V, Arana E, Barrios M, Bartrés A, Cruz J, Montero $\mathrm{R}$, et al. Differentiation of benign and malignant lung lesions: dual-energy computed tomography findings. Eur J Radiol 2016;85:1765-1772

48. Li M, Zheng X, Li J, Yang Y, Lu C, Xu H, et al. Dual-energy computed tomography imaging of thyroid nodule specimens: comparison with pathologic findings. Invest Radiol 2012;47:58-64

49. Kan WC, Wiley AL Jr, Wirtanen GW, Lange TA, Moran PR, Paliwal BR, et al. High Z elements in human sarcomata: assessment by multienergy CT and neutron activation analysis. AJR Am J Roentgenol 1980;135:123-129 